Alma Mater Studiorum - Università di Bologna DEPARTMENT OF ECONOMICS






\title{
Scholarships vs. training for happiness gained from education in creativity: an analytical model
}

\author{
Fabio Zagonari \\ Dipartimento di Scienze Economiche, Università di Bologna \\ via Angherà 22, 47921 Rimini (Italy) Phone: 00390541434135 Fax: 00390541434120 \\ E-mail: fabio.zagonari@unibo.it
}

February 2015

\begin{abstract}
This paper presents an analytical model of the dynamic interrelationships between education, creativity, and happiness based on both theoretical insights and recent empirical neurological studies. In the model, the outcome is conditional on individual intelligence and risk aversion. Specifically, it focuses on two main determinants of creativity (divergent and convergent thinking), and compares two main educational policies (scholarships vs. training) in terms of their impacts on the happiness gained from creativity in the general and healthy population. An empirical test is provided by matching the model's predictions with the results of recent neuroscience research. Numerical simulations suggested that improving convergent thinking is more important than improving divergent thinking for creativity to generate happiness throughout an individual's life, provided both divergent and convergent thinking have achieved a sufficiently large degree; and that unstructured training in divergent thinking (e.g., in accounting schools) is necessary to reach richer but less intelligent people, whereas scholarships or unstructured training in convergent thinking (e.g., in art schools) are necessary to reach more intelligent but less rich people.
\end{abstract}

Keywords: Education, training, happiness, creativity, analytical model

JEL classification: I1, I3, Z1 


\section{Introduction}

For several decades, researchers have reported contradictory results on the hemispheric specialisation of creative thinking (Mihov et al., 2010), and there have been methodological doubts about overgeneralisation of the concept of creativity (Abraham et al., 2012b) and about the loci of brain activity during a task (Takeuchi et al., 2011a). Nonetheless, some recent neuroscience based on functional magnetic resonance imaging (fMRI) has suggested two main determinants of creativity: divergent thinking (Benedek et al., 2014b; Takeuchi et al., 2012), which has also been called unrelated thought (Bernhardt et al., 2014), and convergent thinking (Benedek et al., 2011), which has also been called concept enlargement (Rutter et al., 2012), conceptual expansion (Kröger et al., 2012), remote association (Jung et al., 2013), and novel association (Tong et al., 2013). In this paper, I will standardize on the terminology "convergent thinking", which emphasizes the goal of finding a correct solution to a problem by following a particular set of logical steps, and "divergent thinking", which emphasizes the goal of generating creative ideas by exploring many possible solutions: ideas and information from divergent thinking could be organised and structured using convergent thinking.

Note that working memory or fluid intelligence (Vartanian et al., 2013) or creative evaluation (Ellamil et al., 2012) could be considered as preliminary or ancillary determinants of creativity. In this paper, I will not account for these factors.

Moreover, many neurological studies have shown that education or training can improve both convergent and divergent thinking, whereas problem-solving can be tackled by manipulation without requiring education or training (Deininger et al., 2012): see Fink et al. (2010, 2012), Jung et al. (2010a), Heidarie et al. (2011), Kröger et al. (2013), Luo et al. (2013), Wei et al. (2014) on divergent thinking, and see Spencer et al. (2013) and Ukkola-Vuoti et al. (2013) on convergent thinking.

Note that sleep (Ritter et al., 2012) and mood (Akbari Chermahini \& Hommel, 2012) have been shown to affect creativity. In this paper, I will not account for these factors.

Finally, a recent psychological study, based on verbal free-association tasks, suggested that creativity can put people in a more positive affective state (Brunyé et al., 2013); that is, it can make them more able to experience positive emotions such as happiness.

Note that creativity could be justified as an instinct that evolved as a foraging strategy to cope with a suboptimal environment that required the recombination of information units into novel arrangements and structures (Hoffecker, 2012), or as a way to signal potential mates by improving the ability to read a receiver's mind based on novel conceptual combinations and communication of previously unnoticed relational connections (McKeown, 2013). In this paper, I will refer to these instincts to justify happiness from creativity for the elderly.

However, there have been no theoretical models of the dynamic interactions among education, creativity, and happiness. Indeed, computational models have been developed to simulate the creative process (Collins \& Koechlin, 2012; Lopez-Ortega, 2013), and theoretical models (Chakravarty, 2010) have been developed to simulate processes related to creativity such as those related to the executive function (Sanz de Acedo Lizaraga et al., 2012) or analogical reasoning (Speed, 2010).

The purpose of the present study was to develop a dynamic model capable of accounting for the two main determinants of creativity (i.e., divergent and convergent thinking), and to use the model to compare the impacts of two common educational policies (i.e., offering scholarships vs. curriculum development) on the happiness gained from creativity in the healthy general population.

In this research, I will not attempt to account for gender differences (Abraham et al., 2014; Tarasova et al., 2010b; Volf et al., 2010) or specific tasks such as musical improvisation (Berkowitz \& Ansari, 2010), freestyle rap (Liu et al., 2012), verbal creativity (Benedek et al., 2014a; Green et al., 2012; Rodionov, 2013; Vartanian, 2012; Zhu et al., 2013), creative writing (Shah et al., 2013), or figural (e.g., artistic) creativity (Aziz-Zadeh et al., 2013; Duff et al., 2013; Gansler et al., 2011; Heilman \& Acosta, 2013; Huang et al., 2013). Moreover, I will not consider creativity as a therapy 
for unhealthy people who are affected by autism, Parkinson's disease, epilepsy (Schott, 2012), psychopathology (Jung et al., 2010a, brain lesions (Abraham et al., 2012a; Shamay-Tsoory et al., 2011), bipolar disorder (Ricciardiello \& Fornaro, 2013), schizophrenic thoughts (Fink et al., 2014), mood disorders or dementia (De Souza et al., 2010), or brain lesions (Barbey et al., 2013). Finally, I will also not account for the effects of cannabis (Schafer et al., 2012), drugs (Muller et al., 2013; Reedijk et al., 2013), or electrical stimulation (Kuo \& Nitsche, 2012) to improve creativity.

\section{The analytical model}

In this section, I will propose mathematical formulas that represent the dynamic interrelationships among education, creativity, and happiness. These equations are based on empirical neurological studies, and individual intelligence and risk aversion are important factors. Specifically, I will account for the following variables:

- $\quad$ Each creative experience $k$ takes place at time $t$ as one combination (e.g., couples, triples, ...) of all feasible combinations $\left(p_{0}\right)$ of $n_{0}$ elements: $p_{0}=n_{0}$ ! / [( $\left.\left.n_{0}-k\right) ! k !\right]$. Here, I have used element to represent a thing or a property that can be combined with another thing or property to generate a creative solution. For example, at $t=2$ one looks for couples, at $t=3$ one searches for triples, and so on.

- The set of the $n_{0}$ elements increases at a constant rate for each time $t$ as a result of education or training ( $e$ in $\{0,1\}$ with $e=0$ and $e=1$ in the presence and absence of education or training, respectively) and to a different extent according to a curriculum dedicated to convergent thinking $(\gamma$ in $[0,1]$, where 0 and 1 represent the minimum and the maximum increase in elements, respectively, i.e., no increase and an additional element for each time $t$ or for each creative experience $k): n^{\prime}(k)=\gamma e$ and $n(0)=n_{0}$ so $n_{k}=\gamma k e+n_{0}$ and $p_{k}=\left(\gamma k e+n_{0}\right)$ ! / [ $(\gamma k e$ $\left.+n_{0}-k\right)$ ! $k$ !]. In other words, the number of elements to be combined increases with increasing education or training.

- The same creative experience $k$ produces a smaller happiness $(H)$ if it is related to a larger set of all feasible combinations: $H=k / p_{k}$. For example, one obtains a smaller happiness in discovering 1 out of 252 feasible quintuples of 10 elements.

- The number of combinations that is experienced increases in the presence of a curriculum dedicated to divergent thinking ( $\alpha$ in $[0,1]$, where 0 and 1 represent the minimum and maximum number of creative experiences, respectively, i.e., no experiences and a number of experiences close to $n$ since $[k(n-k) ! k !] / n !=1$ if $k$ is close to $n): H=k / p_{k}$ if $k \leq \alpha e p_{k}$, but $H=0$ if $k>\alpha e p_{k}$. In other words, without education or training, the combinations experienced stop at a small recombination (say, couples or triples)

- Acquiring education or training requires an effort $(E)$, which is smaller for smarter people ( $\beta$ in $[0,1]$, where 0 and 1 represents minimum and maximum effort, respectively): $E=\beta e$. For example, one could bear a large learning cost to attend a lyceum.

- The choice of education or training is based on the discounted value of future happiness gained from creativity, net of the present (opportunity) costs of creativity $(\delta$ in $[0, \infty[$, where 0 and $\infty$ represent the minimum and maximum focus on the present net benefits from learning, respectively). In other words, a larger discount factor depicts less rich or more risk-averse individuals.

If we assume perfect foresight, a rational individual will choose a learning approach rather than a non-learning approach if the respective utilities $\left(U_{\mathrm{L}}\right.$ and $\left.U_{\mathrm{N}}\right)$ meet the following condition:

where

$$
U_{\mathrm{L}}>U_{\mathrm{N}} \text { iff } \beta<f(\alpha, \gamma, \delta)
$$

$$
\begin{gathered}
U_{\mathrm{L}}=\int_{0}^{n}\left[\left(k / p_{k} \text { if } k \leq \alpha e p_{k}, \text { or } 0 \text { if } k>\alpha e p_{k}\right)-\beta\right] E^{(-\delta k)} \mathrm{dk} \\
U_{\mathrm{N}}=\int_{0}^{\mathrm{n} 0}\left(k / p_{0} \text { if } k \leq \alpha e p_{0}, \text { or } 0 \text { if } k>\alpha e p_{0}\right) E^{(-\delta k)} \mathrm{dk}
\end{gathered}
$$


And where $f(\alpha, \gamma, \delta)$ is the implicit value of the learning effort $\beta$, as dependent on the discount rate $(\delta)$ and on a curriculum dedicated to divergent $(\alpha)$ and convergent $(\gamma)$ thinking, such that a rational individual is indifferent between the learning and the non-learning approach.

In this analysis, I can set $n_{0}=2$ and $n=10$, without loss of generality, since the purpose is to compare learning and non-learning approaches, at a given potential sequence of creative experiences.

Note that, for the sake of simplicity, the opportunity cost of education is assumed to be the same for a curriculum dedicated to divergent and convergent thinking: think of years at school or university. Moreover, for the sake of generality, education for divergent and convergent thinking are measured in terms of percentages of maximum outcomes: either teaching strategies or proportion of total curriculum could be thought to be adopted to achieve these outcomes. Finally, normalising $\alpha$ in $[0,1]$ implies that $n$ depicts the maximum length of an individual's creative period (i.e., an individual's life), whereas normalising $\gamma$ in $[0,1]$ implies that $\beta$ in $[0,1]$ depicts the opportunity costs of creativity in terms of the happiness generated by creativity (i.e., smaller for more intelligent people). This is supported by the experiments carried out by Volf \& Tarasova (2013).

\section{An empirical test}

In this section, I will provide a test of the analytical model developed in the previous section by comparing the model's predictions with recent results from neuroscience. Specifically, the following insights are relevant:

1. Insight 1: Adults outperformed adolescents in trials of divergent thinking (Kleibeuker et al., 2013).

2. Insight 2: Activation in the left uni-modal area was observed in subjects in response to partial changes in an original musical pattern, whereas activation of the prefrontal regions of both hemispheres and of the right insula was observed in subjects in response to extreme modification of the original rhythm (Villareal et al., 2013).

3. Insight 3: There is a loss of grey matter volume in the right inferior parietal lobe in very old individuals. This brain region is involved in cognitive functions such as working memory and creativity (Patterson \& Perlstein, 2011), although to a smaller extent in subjects who have an open personality, which represents an increased willingness to experience new things (Taki et al., 2013).

Figure 1. Net benefits $(H-E)$ from learning (solid lines) (i.e., $e=1$ ) and non-learning (dashed lines) (i.e., $e=0$ ) approaches if $\alpha=0.5, \beta=0.1$, and $\gamma=0.5$. Small education in divergent and convergent thinking increases the length of an individual's creative period to a small extent (i.e., from $k=0.5$ to $k=1.5$ ).

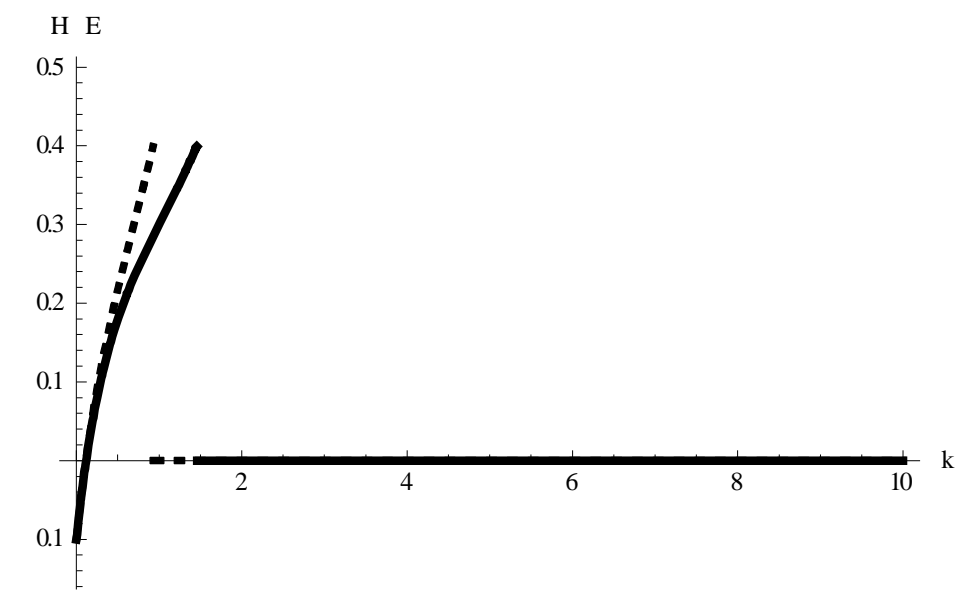


Figure 2. Net benefits $(H-E)$ from learning (solid lines) (i.e., $e=1$ ) and non-learning (dashed lines) (i.e., $e=0$ ) approaches if $\alpha=1, \beta=0.1$, and $\gamma=0.5$. Large education in divergent thinking and small education in convergent thinking increases the length of an individual's creative period to a greater extent (i.e., from $k=0.5$ to $k=2.5$ ).

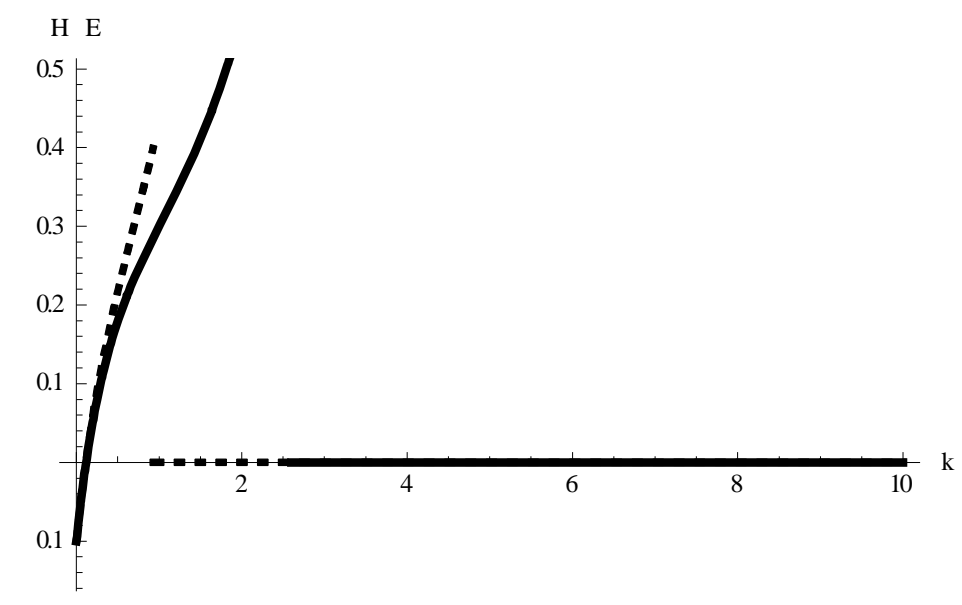

Figure 3. Net benefits $(H-E)$ from learning (solid lines) (i.e., $e=1$ ) and non-learning (dashed lines) (i.e., $e=0$ ) approaches if $\alpha=0.5, \beta=0.1$, and $\gamma=1$. Small education in divergent thinking and large education in convergent thinking increases the length of an individual's creative period to its maximum (i.e., from $k=0.5$ to $k=10$ ).

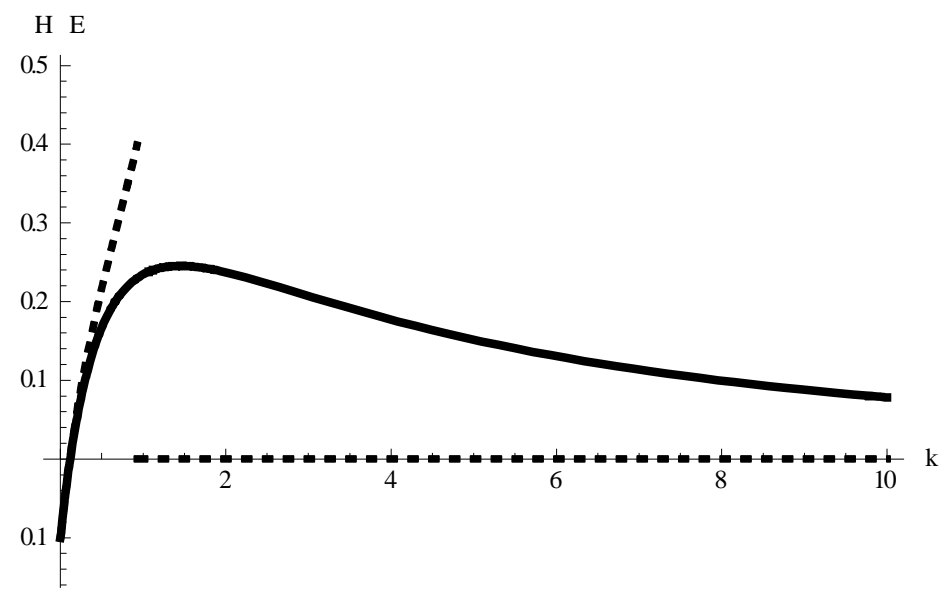

Figure 4. Net benefits $(H-E)$ from learning (solid lines) (i.e., $e=1)$ and non-learning (dashed lines) (i.e., $e=0)$ approaches if $\alpha=0.5$ or $1, \beta=0.1$, and $\gamma=1$. Large education in divergent and convergent thinking increases the length of an individual's creative period to its maximum (i.e., from $k=0.5$ to $k=10$ ).

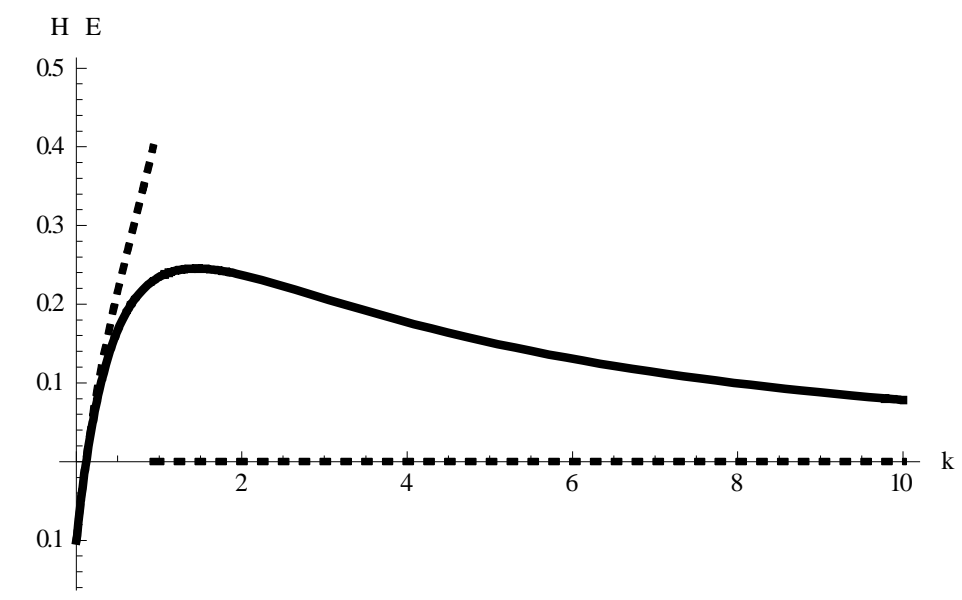

Figure 3 and Figure 4 depict insight 1. When the happiness generated by creativity is coupled with a constant opportunity cost of creativity, the greatest net benefits are observed for intermediate values of $k$. In other words, although the pleasure from designing or discovering something new is at its 
maximum for children and adolescents, but it does not arise only from artistic expression (i.e., almost everything is a creative activity for children, and the happiness gained from creativity is therefore overestimated for most children), most of the cognitive and non-cognitive skills that underlie forms of creative endeavour are acquired before age 20, while the prefrontal cortex is still malleable.

Comparing Figure 1 with Figure 3 (i.e., an increase in $\gamma$ from 0.5 to 1 with $\alpha$ at 0.5 ) and Figure 1 with Figure 2 (i.e., an increase in $\gamma$ from 0.5 to 1 with $\alpha$ at 1) confirms insight 2. Indeed, only an increase in convergent thinking increased the happiness gained from creativity, provided that a sufficiently large divergent thinking was achieved.

Figure 3 and Figure 4 depict insight 3. Indeed, decreasing future happiness gained from creativity is coupled with a present constant cost of creativity, and consequently, decreasing net benefits are observed for large $k$. In other words, individuals find pleasure in things that are easier than creative expression (e.g., sex or violence; hunting, fishing, or eating; accumulating things or discovering new lands), and although all of these instincts represented important survival strategies during various phases of human evolution, these instincts become less and less important with age (i.e., happiness from creativity is generally underestimated for the elderly).

Table 1 summarises the simulations carried out in Figure 1 to Figure 4, in which $\beta$ was fixed at 0.1 , the mean of values which turn out to be significant in the simulations that I will perform in Section 4.

Table 1. Insights from the numerical simulation conducted for alternative values of $\alpha$ and $\gamma$ but with constant $\beta$ (0.1). $N$ means "happiness is not obtained from creativity throughout an individual's life", whereas $H$ means "happiness is obtained from creativity throughout an individual's life".

\begin{tabular}{|c|c|c|c|}
\hline & $\gamma=0$ & $\gamma=0.5$ & $\gamma=1$ \\
\hline$\alpha=0$ & $N$ & $N$ & $N$ \\
\hline$\alpha=0.5$ & $N$ & $N$ (Figure 1) & $H$ (Figure 3) \\
\hline$\alpha=1$ & $N$ & $N$ (Figure 2) & $H$ (Figure 4) \\
\hline
\end{tabular}

Therefore, these numerical simulations show that improving convergent thinking (see $\mathrm{Wu}$ et al., 2014; Yueh et al., 2013) is more important than improving divergent thinking to gain happiness from creativity over the whole life span, (see Alfonso-Benlliure et al., 2013; Davies et al., 2013), once these have both achieved a sufficiently large degree. This is supported by a meta-analysis of functional imaging data performed by Gonen-Yaacovi et al. (2013).

Note that a value of divergent thinking smaller than its maximum seems to be consistent with happiness arising from psychological solidity and social acceptability: consider, for example, the lack of happiness of individuals who oppose any rule. However, the focus on individual happiness gained from creativity does not allow interpersonal comparisons of the relative importance of divergent and convergent thinking at the same achieved creativity level. Consider, for example, Bach's "Well-tempered clavier" (BWV 846-893) and his last and incomplete work "The art of fugue" (BWV 1080), in which convergent thinking seems to prevail over divergent thinking, coupled with Bach's social status. In contrast, consider Van Gogh (e.g., the many "self-portraits" as well as his last painting, "Melancholia"), for whom his psychological distress was accompanied by a situation in which divergent thinking seems to prevail over convergent thinking.

\section{Scholarships vs. training}

In this section, I will try to identify which of the two educational policies would maximise the number of individuals who could benefit from the happiness gained from creativity over their whole lifespan by interpreting both $\beta$ and $\delta$ as self-selection social parameters. In particular, a large $\beta$ is associated with people who will never choose a lyceum, given its high opportunity cost in terms of the learning effort. A large $\delta$ is associated with people who will never choose a lyceum given its high opportunity cost in terms of lost income. 
Figure 5 shows that education in only divergent thinking (thin line) will reach (i.e., it will be chosen by rational individuals) less rich people but exclude less intelligent people, whereas education in only convergent thinking (thick line) will exclude (i.e., it will not be chosen by rational individuals) less rich people but reach less intelligent people.

Figure 5. Couples of $\beta$ and $\delta$ (the areas below the two curves) such that a curriculum dedicated to creativity will be chosen by rational individuals: $\alpha=1$ and $\gamma=0.5$ (thin line) vs. $\alpha=0.5$ and $\gamma=1$ (thick line). Intelligent and rich people will choose educational curricula related to both divergent and convergent thinking (dark grey shading near the origin), less intelligent people would not choose education related to divergent thinking (light grey shading near the $y$-axis), and less rich people would not choose education related to convergent thinking (light grey shading near the $x$-axis).

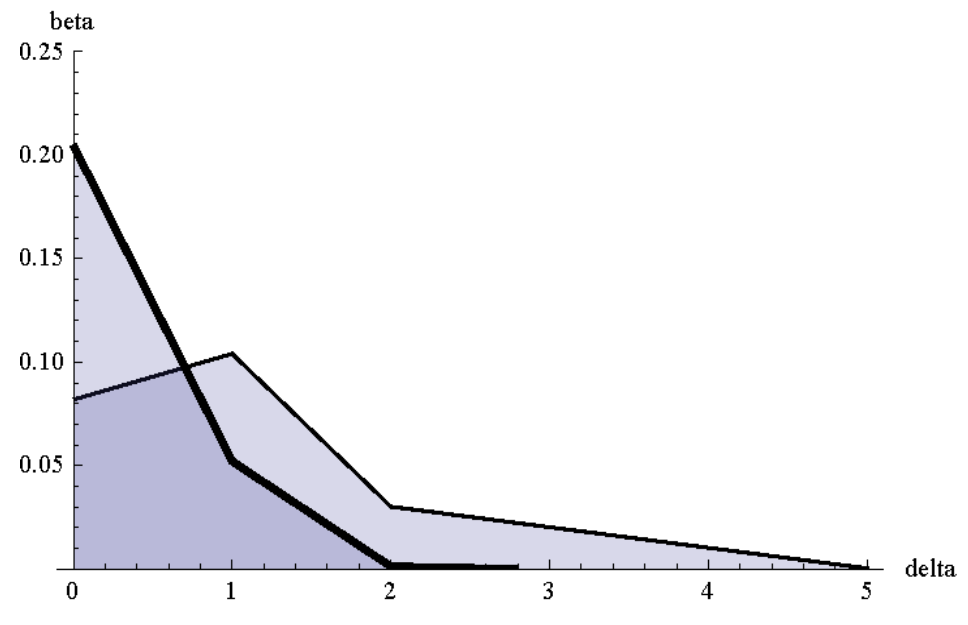

However, happiness from creativity lasts a whole life only if both convergent and divergent thinking are sufficiently large. For example, we could assume that receiving a structured education in the ancient Greek or Latin languages (e.g., in a lyceum) would improve convergent thinking (i.e., by teaching one to combine words, grammatical rules, and meanings in translations), and receiving a structured education in philosophy (e.g., in a lyceum) would improve divergent thinking (i.e., by teaching one to expand concepts or to use analogical reasoning). In contrast, we could assume that a formal education in accounting does not improve divergent thinking, and that a formal education in the arts does not improve convergent thinking. Based on these assumptions, my numerical simulations suggest a possible strategy: unstructured training in divergent thinking for people who would avoid a lyceum because of the learning effort (e.g., people who would rationally choose an accounting school); and scholarships or unstructured training in convergent thinking for people who would avoid a lyceum because of the lost income (e.g., people who would rationally choose an art school), where scholarships would provide an incentive for them to enter a lyceum. In other words, informal training in divergent thinking would be best to reach people at the top left area in Figure 5, whereas scholarships or informal training in convergent thinking would be best to reach people at the bottom right of Figure 5.

Note that training in convergent thinking is easier than training in divergent thinking (McCarty, 2013), and that training in mental computation is considered by some scholars to be bad for creativity (Takeuchi et al., 2011c), even though mathematics training can improve happiness for those who recognize the beauty of mathematics. It's important to note that the distinction between disciplines that foster or impede creativity does not amount to a distinction between the liberal arts (e.g., architecture, mathematics, science, fine arts, and language) and the non-liberal arts (e.g., accounting). This is confirmed by the fact that mathematics is generally considered to be one of the liberal arts, but not one that is generally considered to foster creativity. Moreover, I spoke of unstructured training rather than a dedicated curriculum. Otherwise, people might not choose an accounting school if a course in philosophy was introduced, and might not choose an art school if a course in the ancient Greek or Latin languages was introduced. Finally, the rationality of learning vs. non-learning choices depends on the net benefits obtained from happiness. After all, current and 
future income or job opportunities also account for someone's preferences for a particular educational curriculum and can influence their future happiness.

\section{Discussion}

In this paper, I developed an original analytical model that explains some empirical results from neuroscience and confirms some insights from theoretical studies. The main weaknesses of this paper are the following:

I disregarded the impacts on creativity of the surrounding context, such as encouragement and support from parents, and of other people, as in the case of a thought-provoking classroom (see $\mathrm{Gu}$ et al. 2014; McLellan and Nicholl, 2013). However, the education parameter $(e)$ and the learning effort parameter $(\beta)$, respectively, could depict these features.

I also assumed that individuals show perfect foresight in choosing education, although in reality, it is likely that people might not properly anticipate the happiness to be gained from creativity. Complementary policies would therefore be required. For example, a campaign could be conducted to alert employees to the creative potential of any job. However, it is clear that many other factors would affect these choices.

I assumed that a dedicated curriculum (e.g., in an accounting school, in a lyceum, in an art school) could increase divergent and convergent thinking. Complementary research would be required to confirm this hypothesis. For example, a non-linear econometric model such as the following could provide insights into the impacts of alternative curricula on creativity: $C_{i t}=\alpha \mathrm{SE}_{i t}\left(\delta \mathrm{FI}_{i t}\right)+\gamma \mathrm{SE}_{i t}(\delta$ $\left.\mathrm{FI}_{i t}, \beta \mathrm{SM}_{i t}\right)+\alpha \gamma \mathrm{SE}_{i t}+\mu_{i} .+\mu_{t}+\varepsilon_{i t}$ where $C_{i t}$ represents the creativity level for individual $i$ at time $t$, FI stands for family income, SE for secondary education, and SM for school marks, and $\mu_{i}$. and $\mu_{t}$ represent individual and time effects, such as initial levels of creativity or previous education choices, and $\varepsilon_{i t}$ represents an error term. However, this would require an objective measure of creativity levels or changes in these levels.

I also neglected the uncertainty of happiness gained from creativity. For example, a creative job is often harder to achieve and to keep. However, the discount factor $(\delta)$ could be modified to account for this risk.

\section{Conclusions}

In this paper, I developed and validated a dynamic model of the relationships between happiness and education in creativity. The model suggests that training in divergent thinking would help less intelligent but rich people, whereas intelligent but less rich people would benefit more from training in convergent thinking or scholarships, if the goal is to spread the happiness gained from creativity to more people than at present.

These results rely on recent fMRI neurological studies related to the two main determinants of creativity (i.e., convergent and divergent thinking), for which there is general consensus (unlike in studies of the specific parts of the brain that are activated, for which alternative interpretations exist). For example, high integration of white matter in the brain appears to underlie creativity (Takeuchi et al., 2010), some have suggested the need to further subdivide creativity in order to meaningfully associate creativity with specific neurocognitive processes (Dietrich \& Kanso, 2010), and some of the paradigms behind neuroimaging have been challenged in an effort to advance our understanding of the neurological basis of creativity (Abraham, 2013).

Note that referring to the neuroscience literature let me overcome possible critiques of measures of creativity being concentrated on different sections of its overall spectrum based on the criteria of novelty, usefulness, and surprise (Simonton, 2012). Moreover, this disregards the putative differences between little-c creativity and big-C Creativity based on processes and products rather than on people (Volf \& Tarasova, 2010; Tarasova et al., 2010b). Finally, referring to the neuroscience literature let me avoid issues such as the differences between artistic and scientific creativity (Andreasen \& Ramchandran, 2012). 
Several potential future developments of the framework are possible. First, individuals with a higher tendency to engage in thought unrelated to the task at hand showed an increased thickness of the medial prefrontal cortex and the anterior/mid-cingulate cortex, which are regions of the brain that have been associated with less temporal discounting of monetary rewards in an economic task (Bernhardt et al., 2014). To account for this in the present model, one could make $\alpha$ dependent on $\delta$ or vice-versa. Second, the happiness gained from creativity could be affected by addiction. To account for this, the model could represent this phenomenon by making creative experience $k$ dependent on time $t: k(t)$. One psychological study (Slade, 2009) suggested the effectiveness of an alternating sequence of improvements of convergent thinking, followed by divergent thinking, then convergent thinking, and so on, for people affected by clinical depression. The present model could account for this by making $\alpha(t)$ dependent on $\gamma(t-1)$. The creative productivity could be achieved through "learning by doing". The present model could account for this phenomenon by making $\beta$ dependent on time: $\beta(t)$. Scores for psychometric intelligence appear to reliably predict scores for cognitive flexibility (Duff et al., 2013). The present model could account for this by making $\gamma$ dependent on $\beta$.

\section{References}

Abraham, A. (2013) The promises and perils of the neuroscience of creativity, Frontiers in Human Neuroscience, 7: 246.

Abraham, A., Beudt, S., Ott, D.V.M., Yves Von Cramon, D. (2012a) Creative cognition and the brain: Dissociations between frontal, parietal-temporal and basal ganglia groups, Brain Research, 1482: $55-70$.

Abraham, A., Pieritz, K., Thybusch, K., Rutter, B., Kröger, S., Schweckendiek, J., Stark, R., Windmann, S., Hermann, C. (2012b) Creativity and the brain: uncovering the neural signature of conceptual expansion, Neuropsychologia, 50 (8): 1906-1917.

Abraham, A., Thybusch, K., Pieritz, K., Hermann, C. (2014) Gender differences in creative thinking: behavioral and fMRI findings, Brain Imaging and Behavior, 8 (1): 39-51.

Akbari Chermahini, S., Hommel, B. (2012) More creative through positive mood? Not everyone!, Frontiers in Human Neuroscience, doi: 10.3389/fnhum.2012.00319.

Alfonso-Benlliure, V., Meléndez, J.C., Garcia-Ballesteros, M. (2013) Evaluation of a creativity intervention program for pre-schoolers, Thinking Skills and Creativity, 10: 112-120.

Andreasen, N.C., Ramchandran, K. (2012) Creativity in art and science: are there two cultures?, Dialogues in Clinical Neuroscience, 14 (1): 49-54.

Aziz-Zadeh, L., Liew, S.-L., Dandekar, F. (2013) Exploring the neural correlates of visual creativity, Social Cognitive and Affective Neuroscience, 8 (4): 475-480.

Barbey, A.K., Colom, R., Grafman, J. (2013) Architecture of cognitive flexibility revealed by lesion mapping, NeuroImage, 82: 547-554.

Benedek, M., Beaty, R., Jauk, E., Koschutnig, K., Fink, A., Silvia, P.J., Dunst, B., Neubauer, A.C. (2014a) Creating metaphors: the neural basis of figurative language production, NeuroImage, 90: 99-106.

Benedek, M., Bergner, S., Könen, T., Fink, A., Neubauer, A.C. (2011) EEG alpha synchronization is related to top-down processing in convergent and divergent thinking, Neuropsychologia, 49 (12): 3505-3511.

Benedek, M., Jauk, E., Fink, A., Koschutnig, K., Reishofer, G., Ebner, F., Neubauer, A.C. (2014b) To create or to recall? Neural mechanisms underlying the generation of creative new ideas, NeuroImage, 88: 125-133.

Berkowitz, A.L., Ansari, D. (2010) Expertise-related deactivation of the right temporoparietal junction during musical improvisation, NeuroImage, 49 (1): 712-719.

Bernhardt, B.C., Smallwood, J., Tusche, A., Ruby, F.J.M., Engen, H.G., Steinbeis, N., Singer, T. (2014) Medial prefrontal and anterior cingulate cortical thickness predicts shared individual differences in self-generated thought and temporal discounting, NeuroImage, 90: 290-297. 
Brunyé, T.T., Gagnon, S.A., Paczynski, M., Shenhav, A., Mahoney, C.R., Taylor, H.A. (2013) Happiness by association: breadth of free association influences affective states, Cognition, 127 (1): 93-98.

Chakravarty, A. (2010) The creative brain-revisiting concepts, Medical Hypotheses, 74 (3): 606612.

Collins, A., Koechlin, E. (2012) Reasoning, learning, and creativity: frontal lobe function and human decision-making, PLoS Biology, 10 (3), e1001293.

Davies, D., Jindal-Snape, D., Collier, C., Digby, R., Hay, P., Howe, A. (2013) Creative learning environment in education: a systematic literature review, Thinking Skills and Creativity, 8: 80-91.

De Souza, L.C., Volle, E., Bertoux, M., Czernecki, V., Funkiewiez, A., Allali, G., Leroy, B., Sarazin, M., Habert, M.-O., Dubois, B., Kas, A., Levy, R. (2010) Poor creativity in frontotemporal dementia: a window into the neural bases of the creative mind, Neuropsychologia, 48 (13): 37333742

Deininger, G., Loudon, G., Norman, S. (2012) Modal preferences in creative problem solving, Cognitive Processing, 13 (Suppl. 1): S147-S150.

Dietrich, A., Kanso, R. (2010) A review of EEG, ERP, and neuroimaging studies of creativity and insight, Psychological Bulletin, 136 (5): 822-848.

Duff, M.C., Kurczek, J., Rubin, R., Cohen, N.J., Tranel, D. (2013) Hippocampal amnesia disrupts creative thinking, Hippocampus, 23 (12): 1143-1149.

Ellamil, M., Dobson, C., Beeman, M., Christoff, K. (2012) Evaluative and generative modes of thought during the creative process, NeuroImage, 59 (2): 1783-1794.

Fink, A., Grabner, R.H., Gebauer, D., Reishofer, G., Koschutnig, K., Ebner, F. (2010) Enhancing creativity by means of cognitive stimulation: evidence from an fMRI study, NeuroImage, 52 (4): 1687-1695.

Fink, A., Koschutnig, K., Benedek, M., Reishofer, G., Ischebeck, A., Weiss, E.M., Ebner, F. (2012) Stimulating creativity via the exposure to other people's ideas, Human Brain Mapping, 33 (11): 2603-2610.

Fink, A., Weber, B., Koschutnig, K., Benedek, M., Reishofer, G., Ebner, F., Papousek, I., Weiss, E.M. (2014) Creativity and schizotypy from the neuroscience perspective, Cognitive, Affective and Behavioral Neuroscience, 14 (1): 378-387.

Gansler, D.A., Moore, D.W., Susmaras, T.M., Jerram, M.W., Sousa, J., Heilman, K.M. (2011) Cortical morphology of visual creativity, Neuropsychologia, 49 (9): 2527-2532.

Gonen-Yaacovi, G., De Souza, L.C., Levy, R., Urbanski, M., Josse, G., Volle, E. (2013) Rostral and caudal prefrontal contribution to creativity: a meta-analysis of functional imaging data, Frontiers in Human Neuroscience, 7: 465.

Green, A.E., Kraemer, D.J.M., Fugelsang, J.A., Gray, J.R., Dunbar, K.N. (2012) Neural correlates of creativity in analogical reasoning, Journal of Experimental Psychology: Learning, Memory and Cognition, 38 (2): 264-272.

Gu, J., Zhang, Y., Liu, H. (2014) Importance of social capital to student creativity within higher education in China, Thinking Skills and Creativity, 12: 14-25

Heidarie, A., Poor, S.B., Poor, F.N. (2011) Effects and evaluation of creativity instructional methods on creativity of students, Life Science Journal, 8 (4): 402-408.

Heilman, K.M., Acosta, L.M. (2013) Visual artistic creativity and the brain, Progress in Brain Research, 204: 19-43.

Hoffecker, J.F. (2012) The evolutionary ecology of creativity, Developments in Quaternary Science, 16: 89-102.

Huang, P., Qiu, L., Shen, L., Zhang, Y., Song, Z., Qi, Z., Gong, Q., Xie, P. (2013) Evidence for a left-over-right inhibitory mechanism during figural creative thinking in healthy nonartists, Human Brain Mapping, 34 (10): 2724-2732.

Jung, R.E., Grazioplene, R., Caprihan, A., Chavez, R.S., Haier, R.J. (2010a) White matter integrity, creativity, and psychopathology: disentangling constructs with diffusion tensor imaging, PLoS ONE, 5 (3), e9818. 
Jung, R.E., Mead, B.S., Carrasco, J., Flores, R.A. (2013) The structure of creative cognition in the human brain, Frontiers in Human Neuroscience, doi: 10.3389/fnhum.2013.00330.

Jung, R.E., Segall, J.M., Bockholt, H.J., Flores, R.A., Smith, S.M., Chavez, R.S., Haier, R.J. (2010b) Neuroanatomy of creativity, Human Brain Mapping, 31 (3): 398-409.

Kleibeuker, S.W., Koolschijn, P.C.M.P., Jolles, D.D., de Dreu, C.K.W., Crone, E.A. (2013) The neural coding of creative idea generation across adolescence and early adulthood, Frontiers in Human Neuroscience, doi: 10.3389/fnhum.2013.00905.

Kröger, S., Rutter, B., Hill, H., Windmann, S., Hermann, C., Abraham, A. (2013) An ERP study of passive creative conceptual expansion using a modified alternate uses task, Brain Research, 1527: 189-198.

Kröger, S., Rutter, B., Stark, R., Windmann, S., Hermann, C., Abraham, A. (2012) Using a shoe as a plant pot: neural correlates of passive conceptual expansion, Brain Research, 1430: 52-61.

Kuo, M.-F., Nitsche, M.A. (2012) Effects of transcranial electrical stimulation on cognition, Clinical EEG and Neuroscience, 43 (3): 192-199.

Liu, S., Chow, H.M., Xu, Y., Erkkinen, M.G., Swett, K.E., Eagle, M.W., Rizik-Baer, D.A., Braun, A.R. (2012) Neural correlates of lyrical improvisation: an fMRI study of freestyle rap, Scientific Reports, 2, 834

López-Ortega, O. (2013) Computer-assisted creativity: emulation of cognitive processes on a multiagent system, Expert Systems with Applications, 40 (9): 3459-3470.

Luo, J., Li, W., Qiu, J., Wei, D., Liu, Y., Zhang, Q. (2013) Neural basis of scientific innovation induced by heuristic prototype, PLoS ONE, 8 (1), e49231.

McCarty, C. (2013) Teaching for creativity: from theory to practice, International Journal of Pedagogy and Curriculum, 19 (2): 1-14.

McKeown, G.J. (2013) The analogical peacock hypothesis: the sexual selection of mind-reading and relational cognition in human communication, Review of General Psychology, 17 (3): 267-287. McLellan, R., Nicholl, B. (2013) Creativity in crisis in design \& technology: are classroom climates conductive for creativity in English secondary schools? Thinking Skills and Creativity, 9: 165-185.

Mihov, K.M., Denzler, M., Förster, J. (2010) Hemispheric specialization and creative thinking: a meta-analytic review of lateralization of creativity, Brain and Cognition, 72 (3): 442-448.

Müller, U., Rowe, J.B., Rittman, T., Lewis, C., Robbins, T.W., Sahakian, B.J. (2013) Effects of modafinil on non-verbal cognition, task enjoyment and creative thinking in healthy volunteers, Neuropharmacology, 64: 490-495.

Patterson, M., Perlstein, S. (2011) Good for the heart, good for the soul: the creative arts and brain health in later life, Generations, 35 (2): 27-36.

Reedijk, S.A., Bolders, A., Hommel, B. (2013) The impact of binaural beats on creativity, Frontiers in Human Neuroscience, doi: 10.3389/fnhum.2013.00786.

Ricciardiello, L., Fornaro, P. (2013) Beyond the cliff of creativity. A novel key to bipolar disorder and creativity, Medical Hypotheses, 80 (5): 534-543.

Ritter, S.M., Strick, M., Bos, M.W., Van Baaren, R.B., Dijksterhuis, A. (2012) Good morning creativity: task reactivation during sleep enhances beneficial effect of sleep on creative performance, Journal of Sleep Research, 21 (6): 643-647.

Rodionov, A.R. (2013) Brain mechanisms of imagination in solving creative verbal tasks, Human Physiology, 39 (3): 256-264.

Rutter, B., Kröger, S., Stark, R., Schweckendiek, J., Windmann, S., Hermann, C., Abraham, A. (2012) Can clouds dance? Neural correlates of passive conceptual expansion using a metaphor processing task: implications for creative cognition, Brain and Cognition, 78 (2): 114-122.

Sanz de Acedo Lizarraga, M.L., Sanz de Acedo Baquedano, M.T., Villanueva, O.A. (2012) Critical thinking, executive functions and their potential relationship, Thinking Skills and Creativity, 7 (3): 271-279.

Schafer, G., Feilding, A., Morgan, C.J.A., Agathangelou, M., Freeman, T.P., Valerie Curran, H. (2012) Investigating the interaction between schizotypy, divergent thinking and cannabis use, Consciousness and Cognition, 21 (1): 292-298. 
Schott, G.D. (2012) Pictures as a neurological tool: lessons from enhanced and emergent artistry in brain disease, Brain, 135 (6): 1947-1963.

Shah, C., Erhard, K., Ortheil, H.-J., Kaza, E., Kessler, C., Lotze, M. (2013) Neural correlates of creative writing: an fMRI Study, Human Brain Mapping, 34 (5): 1088-1101.

Shamay-Tsoory, S.G., Adler, N., Aharon-Peretz, J., Perry, D., Mayseless, N. (2011) The origins of originality: the neural bases of creative thinking and originality, Neuropsychologia, 49 (2): 178-185. Simonton, D.K. (2012) Quantifying creativity: can measures span the spectrum?, Dialogues in Clinical Neuroscience, 14 (1): 100-104.

Slade, M. (2009) Personal recovery and mental illness, Cambridge University Press, Cambridge.

Speed, A. (2010) Abstract relational categories, graded persistence, and prefrontal cortical representation, Cognitive Neuroscience, 1 (2): 126-137.

Spencer, J.R., Anderson, K.M., Ellis, K.K. (2013) Radiant thinking and the use of the mind map in nurse practitioner education, Journal of Nursing Education, 52 (5): 291-293.

Takeuchi, H., Taki, Y., Hashizume, H., Sassa, Y., Nagase, T., Nouchi, R., Kawashima, R. (2011a) Cerebral blood flow during rest associates with general intelligence and creativity, PLoS ONE, 6 (9), e25532.

Takeuchi, H., Taki, Y., Hashizume, H., Sassa, Y., Nagase, T., Nouchi, R., Kawashima, R. (2011b) Failing to deactivate: the association between brain activity during a working memory task and creativity, NeuroImage, 55 (2): 681-687.

Takeuchi, H., Taki, Y., Hashizume, H., Sassa, Y., Nagase, T., Nouchi, R., Kawashima, R. (2012) The association between resting functional connectivity and creativity, Cerebral Cortex, 22 (12): 2921-2929.

Takeuchi, H., Taki, Y., Sassa, Y., Hashizume, H., Sekiguchi, A., Fukushima, A., Kawashima, R. (2010) White matter structures associated with creativity: evidence from diffusion tensor imaging, NeuroImage, 51 (1): 11-18.

Takeuchi, H., Taki, Y., Sassa, Y., Hashizume, H., Sekiguchi, A., Fukushima, A., Kawashima, R. (2011c) Working memory training using mental calculation impacts regional gray matter of the frontal and parietal regions, PLoS ONE, 6 (8), e23175.

Taki, Y., Thyreau, B., Kinomura, S., Sato, K., Goto, R., Wu, K., Kawashima, R., Fukuda, H. (2013) A longitudinal study of the relationship between personality traits and the annual rate of volume changes in regional gray matter in healthy adults, Human Brain Mapping, 34 (12): 3347-3353.

Tarasova, I.V., Volf, N.V., Razoumnikova, O.M. (2010a) Parameters of cortical interactions in subjects with high and low levels of verbal creativity, Human Physiology, 36 (1): 80-85.

Tarasova, I.V., Volf, N.V., Razumnikova, O.M. (2010b) Changes in the coherence of cortical biopotentials during performance of a verbal creative task in men and women, Neuroscience and Behavioral Physiology, 40 (4): 429-433.

Tong, D.D., Zhu, H.X., Li, W.F., Yang, W.J., Qiu, J., Zhang, Q.G. (2013) Brain activity in using heuristic prototype to solve insightful problems, Behavioural Brain Research, 253: 139-144.

Ukkola-Vuoti, L., Kanduri, C., Oikkonen, J., Buck, G., Blancher, C., Raijas, P., Karma, K., Lähdesmäki, H., Järvelä, I. (2013) Genome-wide copy number variation analysis in extended families and unrelated individuals characterized for musical aptitude and creativity in music, PLoS ONE, 8 (2), e56356.

Vartanian, O. (2012) Dissociable neural systems for analogy and metaphor: implications for the neuroscience of creativity, British Journal of Psychology, 103 (3): 302-316.

Vartanian, O., Jobidon, M.-E., Bouak, F., Nakashima, A., Smith, I., Lam, Q., Cheung, B. (2013) Working memory training is associated with lower prefrontal cortex activation in a divergent thinking task, Neuroscience, 236: 186-194.

Villarreal, M.F., Cerquetti, D., Caruso, S., Schwarcz López Aranguren, V., Gerschcovich, E.R., Frega, A.L., Leiguarda, R.C. (2013) Neural correlates of musical creativity: differences between high and low creative subjects, PLoS ONE, 8 (9), e75427.

Volf, N.V., Tarasova, I.V. (2010) The relationships between EEG $\Theta$ and $\beta$ oscillations and the level of creativity, Human Physiology, 36 (2): 132-138. 
Volf, N.V., Tarasova, I.B. (2013) The influence of reward on the performance of verbal creative tasks: behavioral and EEG effects, Human Physiology, 39 (3): 302-308.

Volf, N.V., Tarasova, I.V., Razumnikova, O.M. (2010) Gender-related differences in changes in the coherence of cortical biopotentials during image-based creative thought: relationship with action efficacy, Neuroscience and Behavioral Physiology, 40 (7): 793-799.

Wei, D., Yang, J., Li, W., Wang, K., Zhang, Q., Qiu, J. (2014) Increased resting functional connectivity of the medial prefrontal cortex in creativity by means of cognitive stimulation, Cortex, 51 (1): 92-102.

Wu, H.-Y., Wu, H.-S., Chen, I.-S., Chen, H.-C. (2014) Exploring the critical influential factors of creativity for college students: a multiple criteria decision-making approach, Thinking Skills and Creativity, 11: 1-21

Yueh, H.-P., Chang, C.-C., Liang, C. (2013) Are there differences between science and engineering majors regarding the imagination-mediated model?, Thinking Skills and Creativity, 10: 79-90

Zhu, F., Zhang, Q., Qiu, J. (2013) Relating inter-individual differences in verbal creative thinking to cerebral structures: an optimal voxel-based morphometry study, PLoS ONE, 8 (11), e79272. 


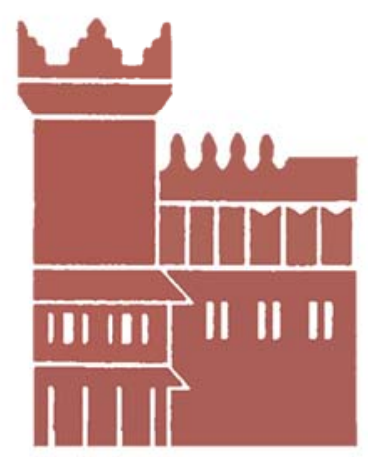

Alma Mater Studiorum - Università di Bologna DEPARTMENT OF ECONOMICS

Strada Maggiore 45

40125 Bologna - Italy

Tel. +39051 2092604

Fax +390512092664

http://www.dse.unibo.it 